\title{
Factor structure of the Chinese version of the geriatric anxiety inventory
}

Ming Guan ${ }^{1,2^{*}}$

\begin{abstract}
Background: As China's population ages, the mental health of older people has been increasingly focused on by academic circles.

Purpose: The aim of this study was to identify the factor structure of the Chinese version of the geriatric anxiety inventory (GAl-CV).

Methods: This study used data collected from Investigation on the anxiety symptoms of the elderly in the city of Beijing supported by scientific research fund project of Renmin University of China. Cronbach's a was used to test internal consistency reliability. Both confirmatory and exploratory factor analyses were performed separately for factor analysis.

Results: 1318 subjects with mean age $71.35 \pm 7.44$ years (male $40.6 \%$ ) were involved. Principal components analysis revealed a three-factor structure of the GAI-CV. GAl-CV scales exhibited good internal consistency (Cronbach's $a=0.937$ ) and a three-factor model fit the data well [comparative fit index $(\mathrm{CFI})=0.891$, root mean square error of approximation (RMSEA) $=0.084$.
\end{abstract}

Conclusions: The Chinese version of the GAl appears to be reliable and valid to measure anxiety for elderly people in China.

Keywords: Factor structure, GAI-CV, Principal components analysis, Confirmatory factor analysis

\section{Background}

Late-life anxiety disorders are chronic and fairly common, but under-diagnosed and undertreated. Anxiety disorders in the elderly are an underestimated cause of distress, disability, and mortality risk [1]. The Generalized Anxiety Inventory (GAI) is a new 20-item self-report or nurseadministered scale developed by Pachana et al. (2007) that measures dimensional anxiety in elderly people [2]. Various versions of GAI, such as Australian version [3], Portuguese version [4], Spanish version [5], GAI-short form [6], Chinese version [7], and Brazilian Portuguese version [8] have demonstrated very good psychometric properties and can be a reliable instrument to measure anxiety in native elderly people. The concurrent validity [9] and predictive validity [10] of the GAI were validated. And GAI in

\footnotetext{
*Correspondence: gming0604@163.com

1 Family Issues Center, Xuchang University, Xuchang, China

Full list of author information is available at the end of the article
}

a duloxetine clinical trial for elderly adults with generalized anxiety disorder was validated [11].

With the fast development of its economy, China has seen the fastest increase in its aging population in the world. The mental health of life of older people is of increasing interest in China, due to its aging population. But there is lack of systematic evidences of aged Chinese with anxiety. While, worst of all, middle-aged persons suffering from anxiety disorder in modern China live poor lives. For example, Wang et al. (2015) indicate that patients with anxiety disorder in China tend to have poor family functioning and quality of life [12]. Hence, I speculate that elderly Chinese populations are prone to expose themselves to anxiety and be tortured by it.

Anxiety is a common mental disorder among older people who live in the city of Beijing [13]. A study in the Xicheng district of Beijing in China shows that anxiety and gloomy mentality are common in old people aged 60-80 years, which is independently associated with

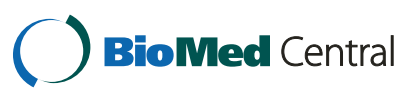

(c) 2016 Guan. This article is distributed under the terms of the Creative Commons Attribution 4.0 International License (http:// creativecommons.org/licenses/by/4.0/), which permits unrestricted use, distribution, and reproduction in any medium, provided you give appropriate credit to the original author(s) and the source, provide a link to the Creative Commons license, and indicate if changes were made. The Creative Commons Public Domain Dedication waiver (http://creativecommons.org/publicdomain/ zero/1.0/) applies to the data made available in this article, unless otherwise stated. 
related factors such as life quality, subjective well-being, social support, and so on [14].

The aim of the current preliminary study was to analyze the factor structure of GAI-CV, both with exploratory and confirmatory methods, and also to provide relevant support for methodological decisions.

\section{Methods}

\section{Data source}

Investigation on the anxiety symptoms of the elderly in the city of Beijing used here was supported by scientific research fund project of Renmin University of China in December 2009. In the case of translation, GAI was translated into Chinese language. The Investigation began from September 2010 and ended in February 2012. All the 60 and above subjects were 1350 community elders from 45 villages and residential communities and 101 institutional elders from Sijiqing Homes For The Elderly and Jia De The Aged Apartment in Beijing. The main demographic variables are age, sex, educational level, hukou, and marital status.

\section{Statistical analysis}

In the first stage, descriptive statistics with socioeconomic indicators and exploratory factor analysis (principal component analysis) with varimax rotation (eigenvalues of greater than one) was carried out with SPSS version 16.0 for Windows (SPSS Inc., Chicago, IL, USA). I next studied item loading on each factor after rotation, considering 0.5 as significant loading. Item lodgings of greater than 0.5 were considered as contributing significantly to a particular factor. Cronbach's $\alpha$ was calculated to measure reliability of each subscale of the GAI-CV represented by the identified factors.

Then I performed a confirmatory factor analysis using the China structure of the GAI using Stata 12.0 (Stata Corporation, Texas, USA). Eight indexes were used to measure goodness of fit: Tucker-Lewis coefficient (TLI), comparative fit index (CFI), root mean square error of approximation (RMSEA), Akaike information index (AIC), Bayesian information criterion (BIC), Standardized root mean squared residual (SRMR), Coefficient of determination (CD), and degree of freedom $(d f)$. CFI assesses fit relative to a null model and ranges from 0 to 1 with values of $0.90-0.95$ indicating acceptable and over 0.95 good fit. TLI adjusts for the number of model parameters and is interpreted as CFI. RMSEA expresses the lack of fit per degree of freedom of the model. Values are interpreted as follows: $<0.05$ indicates very good, $>0.05-0.08$ good, and $>0.10$ poor fit. SRMR is the average of the differences between the observed and predicted correlations and has a range from 0 to 1 . Values of $<0.08$ indicate good fit.
Construct validity is tested using exploratory and confirmatory factor analysis. In this study, reliability was tested using Cronbach's $\alpha$ to assess the internal consistency of the instruments.

\section{Results \\ Sample characteristics}

Participants in this study included 1318 people more than 60 years old who were living in the community. They were randomly selected from 15 communities in Beijing. Basic information was collected in Table 1. Table 1 shows most of subjects were females with education levels less than college level. Regarding ethnicity, only $3.4 \%$ subjects were elders with ethnic minority. Almost $74.3 \%$ of the subjects were married persons.

\section{Principal components analysis}

Kaiser-Meyer-Olkin measure of sampling adequacy was 0.954 , which indicates adequate sample size for the factor analysis. Bartlett's test of sphericity was significant $\left(\mathrm{X}^{2}=1.45 \mathrm{E} 4, d f=190, P<0.001\right)$. Principal components analysis with varimax rotation solution showed four components with an eigenvalue greater than one which accounted for $59.384 \%$ of total variance. Three factors were extracted from the scale. The eigenvalues and explained \% of the variance are shown in Table 2. The reliability of the GAI-CV assessed by Cronbach's $\alpha$ was 0.937 .

See Table 2, component 1 accounted for $38.97 \%$ of the variance and included twelve items, all pertaining to mental descriptions and including a variety of mental

Table 1 Background of study subjects

\begin{tabular}{llcc}
\hline Item & Category & Number & (\%) \\
\hline Gender & Male & 535 & 40.6 \\
\multirow{2}{*}{ Education back- } & Female & 783 & 59.4 \\
ground & Plementary school and below & 418 & 31.8 \\
& Highary school & 324 & 24.6 \\
& $\geq$ College & 251 & 19.0 \\
Ethnicity & Han & 325 & 24.6 \\
& Ethnic minority & 1186 & 90.0 \\
& Missing & 45 & 3.4 \\
Age & $60-69$ & 87 & 6.6 \\
& $70-79$ & 567 & 43 \\
& $>80$ & 553 & 42 \\
Marital status & Married & 198 & 15.0 \\
& Widowed & 980 & 74.3 \\
& Divorced & 263 & 20.0 \\
& Single & 70 & 5.3 \\
Total & & 5 & 0.4 \\
\hline
\end{tabular}


Table 2 Principal component factor analysis with varimax rotation (eigenvalue $>1$ and factor loadings $>0.5$.)

\begin{tabular}{|c|c|c|c|c|c|}
\hline & Mean & SD & Mental anxiety & Negative anxiety & Physical anxiety \\
\hline 1 I worry a lot of the time & 0.15 & 0.354 & 0.478 & & \\
\hline 2 I find it difficult to make a decision & 0.16 & 0.369 & 0.430 & & \\
\hline 3 I often feel jumpy & 0.09 & 0.283 & 0.728 & & \\
\hline 4 I find it hard to relax & 0.11 & 0.318 & 0.741 & & \\
\hline 5 I often cannot enjoy things because of my worries & 0.08 & 0.277 & 0.605 & & \\
\hline 6 Little things bother me a lot & 0.17 & 0.375 & 0.581 & & \\
\hline 7 I often feel like I have butterflies in my stomach & 0.12 & 0.326 & 0.680 & & \\
\hline 9 I cannot help worrying about even trivial thing & 0.18 & 0.380 & 0.601 & & \\
\hline 10 I often feel nervous & 0.11 & 0.307 & 0.712 & & \\
\hline 11 My own thoughts often make me anxious & 0.13 & 0.335 & 0.670 & & \\
\hline 13 I think of myself as a nervous person & 0.11 & 0.317 & 0.592 & & \\
\hline 20 I often feel upset & 0.11 & 0.318 & 0.559 & & \\
\hline 14 I always anticipate the worst will happen & 0.07 & 0.261 & & 0.633 & \\
\hline 15 I often feel shaky inside & 0.05 & 0.227 & & 0.739 & \\
\hline 16 I think that my worries interfere with my life & 0.08 & 0.274 & & 0.645 & \\
\hline 17 My worries often overwhelm me & 0.03 & 0.184 & & 0.755 & \\
\hline 19 I miss out on things because I worry too much & 0.06 & 0.239 & & 0.674 & \\
\hline 81 think of myself as a worrier & 0.18 & 0.387 & & & 0.604 \\
\hline 12 I get an upset stomach due to my worrying & 0.13 & 0.334 & & & 0.722 \\
\hline 18 I sometimes feel a great knot in my stomach & 0.06 & 0.232 & & & 0.595 \\
\hline Eigenvalue & & & 4.676 & 1.260 & 1.206 \\
\hline
\end{tabular}

feelings. Therefore, this component was labeled mental anxiety. Cronbach's $\alpha$ for this component was $\alpha=0.917$. Component two accounted for $10.503 \%$ of the variance and comprised five items. All items featured GAI-CV as the negative ideas will result in poor behavior if subjects could not control themselves. All items on this component were negatively phrased, so that a higher score on each item indicated, e.g., an increase in negative ideas. Given the emphasis on anxiety, this component was named anticipation anxiety. Cronbach's $\alpha$ forth reliability for scale was $\alpha=0.851$. Lastly, component three accounted for $10.049 \%$ of the variance and consisted of four items. All items referred to the physical response to the anxiety. This was the only component to include negative items. The component was named physical anxiety. Internal consistency was $\alpha=0.651$. Hence, internal consistency of the three components was good to excellent.

\section{Confirmatory factor analysis}

The CFA for the 20-items yielded a three-factor model that fitted the data very well as shown in Fig. 1. All-fit indices of the model had a satisfactory goodness of fit $(\mathrm{AIC}=-1532.605, \mathrm{BIC}=-1206.212$, CFI $=0.891$, $\mathrm{TLI}=0.876, \quad \mathrm{RMSEA}=0.084, \mathrm{SRMR}=0.044$, $\mathrm{CD}=0.986$, and $d f=63$ ). The results are that the model fits the data good, and is almost certainly the true model for the relations among those indicators. Moreover, CD is
0.986, which provides in percentage form the amount of predictability in the model.

\section{Discussion}

The objectives of this research were to translate the GAI into the Chinese language (GAI-CV) and to determine the factorial structure and validity of the GAI-CV among a group of elderly Chinese adults. To our knowledge, this is the first attempt to validate the GAI-CV in the old Chinese adults. As a result, the final validated Chinese version of the GAI-CV comprises three subscales: mental anxiety, negative anxiety, and physical anxiety. The first subscale, composed of 12 items, assesses mental health of old adults regarding the results obtained with adopting the behaviors listed, as well as the importance of the elder's perception that others approve or disapprove of performing the behavior. The second subscale, comprising five items, assesses the negative imagines of old adults to identify motives and behaviors related to the mental disorder. Finally, the third subscale, including three items, assesses physical situations of old adults that require of elderly adults decision-making outside their home.

The internal consistency of the GAI-CV was satisfactory. It should be mentioned, however, that the reliability coefficient of the physical anxiety subscale of the Chinese version was below acceptable limits (Cronbach's $\alpha=0.651$ ). This finding is not very surprising given the 


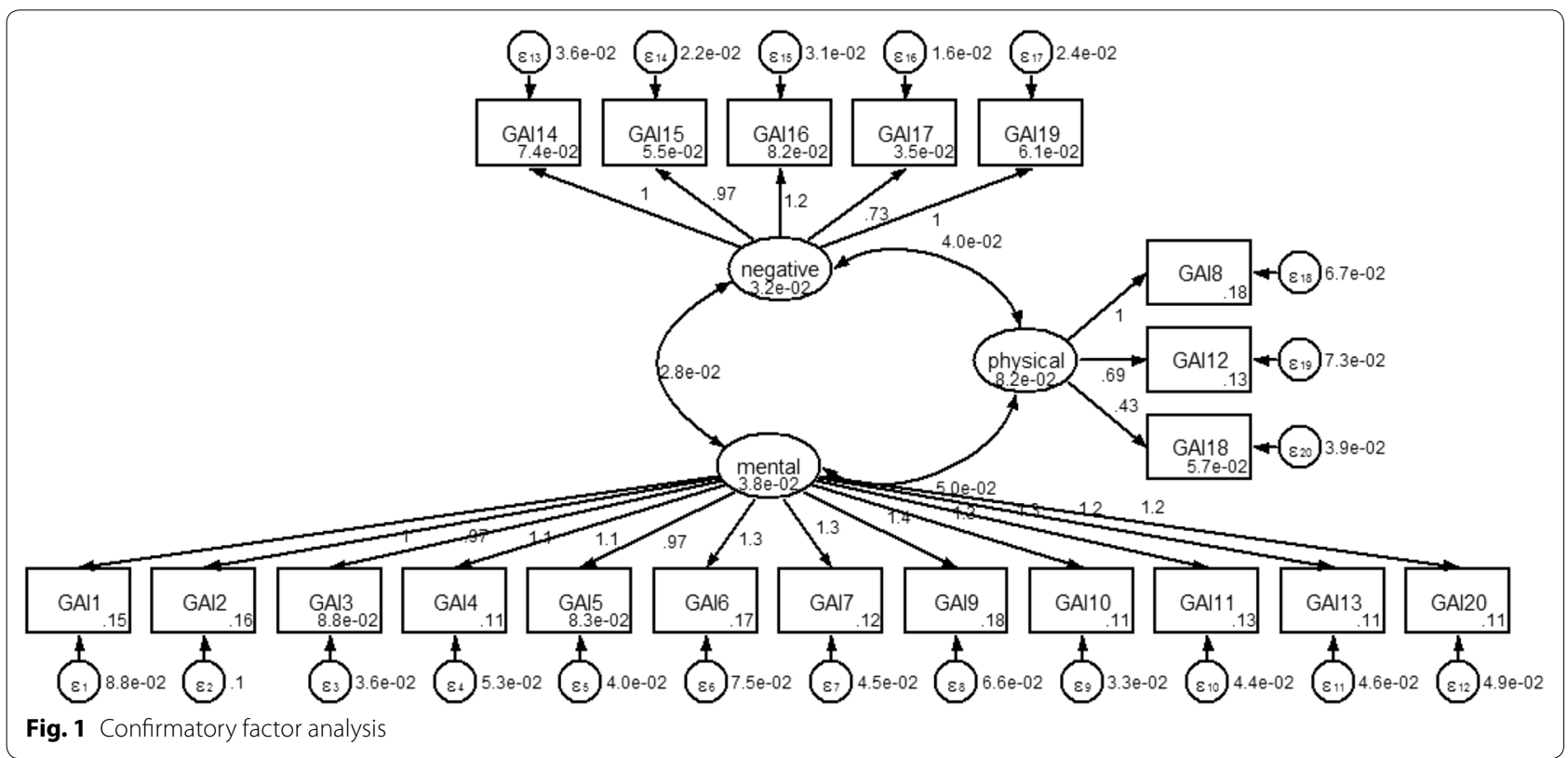

fact that this GAI-CV subscale only consists of three items referring to situations.

A similar study of factor analytic study reveals that persons who exhibited symptoms of anxiety produce more factors. A sample of patients with cognitive impairment revealed a four-factor structure of the GAI through principal components analysis [15]. The difference of factor structure between that of Diefenbach et al. (2014) and mine may lie in that there exists healthy elderly persons in my subjectives.

Other factor analytic studies of Geriatric Anxiety Inventory-Short Form (GAI-SF) also showed the best fit for factor structure. For example, the psychometric properties of a Portuguese version of the GAI-SF showed good internal consistency ( $\alpha=0.77$ ), good convergent, and discriminant validity $(P<0.05)$. The factorial structure presented a single factor that explained $52 \%$ of the variance. The model showed a good fit to the data $\left(\mathrm{x}^{2}=1.233\right.$, TLI $=0.997$, CFI $=0.999$, $\left.\mathrm{RMSEA}=0.020\right)$ [16]. It suggests that GAI-SF may be used as an alternative for GAI-CV.

The factor structure from this study is guessed to be generalized to the whole population in China. Because another study indicates that the GAI and Geriatric Anxiety Scale may be good alternatives to anxiety measures not designed specifically for older adults [17].

Complementally, this study suggests anxiety may come from internal motivation besides shame [18] and empty-nest living arrangement [19]. Thus, upgrade of life attitude may reduce the harm from anxiety prevalence among old population in China.
The findings from this study indicated that improving quality of life in this age group becomes a very important task. Early studies show burnout management [20], mental health tutorship [13], Tai chi [21, 22], and morita therapy [23] should be considered in the city of Beijing. To effectively reduce the anxiety symptoms of the elderly population, this study's finding in addition to those physical activities highlights prevention from mental breakdown.

\section{Conclusions}

The results of this study suggest that the GAI-CV is a valid and reliable tool for measuring anxiety of the elderly adults aged 60 years and above in China Beijing. Based on this study, we can guess anxiety consists of psychological, negative, and physical dimensions. The internal consistency of the GAI-CV scales was found to be satisfactory. Exploratory factor analysis yielded a multiplefactor model, and a CFA demonstrated reasonable fit for a three-factor correlated model in the total sample. Therefore, it can be concluded that the GAI-CV seems to be a promising scale for assessing various aspects of anxiety that is suitable for the elderly adults in China.

The results from China Beijing context suggest GAI-CV has been not only used in studies of Western countries but also applied in the Chinese population. Moreover, the factor analysis shows GAI-CV may be reliable and valid to measure anxiety in other developing countries.

Several limitations of the present study should be noted. A first limitation pertains to normal, psychologically healthy elders, and so the reliability and validity of 
the GAI-CV in clinically referred elders remains to be established. Second, a number of psychometric properties of the GAI-CV remain to be tested. The current study did not examine the test-retest reliability of the GAI-CV, and also the predictive, convergent, divergent, and discriminant validity of the scale need to be investigated.

\section{Author details}

${ }^{1}$ Family Issues Center, Xuchang University, Xuchang, China. ${ }^{2}$ School of Business, Xuchang University, Xuchang, China.

\section{Acknowledgements}

This study was funded by the "Wellbeing and quality of life of minority families migrating from rural to urban areas" sponsored by the Ministry of Education of China Humanities and Social Sciences Research Youth Project Fund (Project number 14YJC630042)

Received: 29 September 2015 Accepted: 7 January 2016

Published online: 28 January 2016

\section{References}

1. Andreescu C, Varon D. New research on anxiety disorders in the elderly and an update on evidence-based treatments. Curr Psychiatry Rep. 2015;17:53. doi:10.1007/s11920-015-0595-8.

2. Pachana NA, Byrne GJ, Siddle H, Koloski N, Harley E, Arnold E. Development and validation of the Geriatric Anxiety Inventory. Int Psychogeriatr. 2007;19(1):103-14.

3. Byrne GJ, Pachana NA, Goncalves DC, Arnold E, King R, Khoo SK. Psychometric properties and health correlates of the Geriatric Anxiety inventory in Australian community-residing older women. Aging Ment Health. 2010;14(3):247-54.

4. Ribeiro O, Paúl C, Simões MR, Firmino H. Portuguese version of the Geriatric Anxiety Inventory: transcultural adaptation and psychometric validation. Aging Ment Health. 2011;15(6):742-8.

5. Márquez-González M, Losada A, Fernández-Fernández V, Pachana NA. Psychometric properties of the Spanish version of the Geriatric Anxiety Inventory. Int Psychogeriatr. 2012;24(1):137-44.

6. Johnco C, Knight A, Tadic D, Wuthrich VM. Psychometric properties of the Geriatric Anxiety Inventory (GAI) and its short-form (GAI-SF) in a clinical and non-clinical sample of older adults. Int Psychogeriatr. 2014;11:1-9.

7. Yan Y, Xin T, Wang D, Tang D. Application of the Geriatric Anxiety Inventory-Chinese Version (GAl-CV) to older people in Beijing communities. Int Psychogeriatr. 2014;26(3):517-23.

8. Massena PN, de Araújo NB, Pachana N, Laks J, de Pádua AC. Validation of the Brazilian Portuguese Version of Geriatric Anxiety Inventory-GAI-BR. Int Psychogeriatr. 2014;20:1-7.
9. Cheung G. Concurrent validity of the Geriatric Anxiety Inventory in latelife depression. Int Psychogeriatr. 2007:19(2):333-5.

10. Boddice G, Pachana NA, Byrne GJ. The clinical utility of the geriatric anxiety inventory in older adults with cognitive impairment. Nurs Older People. 2008;20(8):36-9.

11. Ball SG, Lipsius S, Escobar R. Validation of the geriatric anxiety inventory in a duloxetine clinical trial for elderly adults with generalized anxiety disorder. Int Psychogeriatr. 2015;30:1-7.

12. Wang J, Chen Y, Tan C, Zhao X. Family functioning, social support, and quality of life for patients with anxiety disorder. Int J Soc Psychiatry. 2015 pii: 0020764015584649

13. Zhang B, Song Y, Li X, Lan Z, Li J, Li J, Feng F, Yang F. Analysis on mental health and related factors of community elders in urban Beijing. Chin J clin healthc. 2010;13(4):404-6.

14. Xie Z, Zhang H, Li S, Shao J, Tlan L, Zhao R, Gong J, Han J, Guo W. A follow up study of the anxiety or gloomy mentality in the elderly in Xicheng district of Beijing. Chin J Geriatr. 2013;32(3):341-4.

15. Diefenbach GJ, Bragdon LB, Blank K. Geriatric Anxiety Inventory: Factor Structure and Associations with Cognitive Status. Am J Geriatr Psychiatry. 2014:22(12):1418-26.

16. Daniel F, Espirito-Santo H, Guadalupe S, Silva S. Lemos L.EPA-1716 - the Portuguese geriatric anxiety inventory-short form: psychometric properties. European Psychiatry. 2014;29(Suppl 1):1.

17. Gould CE, Segal DL, Yochim BP, Pachana NA, Byrne GJ, Beaudreau SA. Measuring anxiety in late life: a psychometric examination of the geriatric anxiety inventory and geriatric anxiety scale. J Anxiety Disord. 2014;28(8):804-11.

18. Zhong J, Wang A, Qian M, Zhang L, Gao J, Yang J, Li B, Chen P. Shame, personality, and social anxiety symptoms in Chinese and American nonclinical samples: a cross-cultural study. Depress Anxiety. 2008;25(5):449-60.

19. Wang Z, Shu D, Dong B, Luo L, Hao Q. Anxiety disorders and its risk factors among the Sichuan empty-nest older adults: a cross-sectional study. Arch Gerontol Geriatr. 2013;56(2):298-302.

20. Ding Y, Qu J, Yu X, Wang S. The mediating effects of burnout on the relationship between anxiety symptoms and occupational stress among community healthcare workers in China: a cross-sectional study. PLoS One. 2014;9(9):e107130. doi:10.1371/journal.pone.0107130.

21. Sharma M, Haider T. Tai chi as an alternative and complimentary therapy for anxiety: a systematic review. J Evid Based Complementary Altern Med. 2015:20(2):143-53.

22. Wang F, Lee EK, Wu T, Benson H, Fricchione G, Wang W, Yeung AS. The effects of tai chi on depression, anxiety, and psychological well-being: a systematic review and meta-analysis. Int J Behav Med. 2014;21(4):605-17.

23. Wu H, Yu D, He Y, Wang J, Xiao Z, Li C. Morita therapy for anxiety disorders in adults. Cochrane Database Syst Rev. 2015;. doi:10.1002/14651858. CD008619.pub2.

\section{Submit your next manuscript to BioMed Central and we will help you at every step:}

- We accept pre-submission inquiries

- Our selector tool helps you to find the most relevant journal

- We provide round the clock customer support

- Convenient online submission

- Thorough peer review

- Inclusion in PubMed and all major indexing services

- Maximum visibility for your research

Submit your manuscript at www.biomedcentral.com/submit
() Biomed Central 